\title{
Quality indicators in colonoscopy
}

\author{
Robert Enns MD
}

S everal recent publications (1-3) in the area of quality indicators in endoscopy have influenced endoscopists to continuously assess their practice. Although many specialist societies have specific credentialing requirements for training and ongoing cognitive assessment (4-7), the performance of the technical aspect of endoscopic procedures has been one area for which specific criteria have been difficult to develop.

The Canadian Association of Gastroenterology (CAG) is presently working on recommendations for credentialing of endoscopic procedures, and hopefully these documents will be completed, approved through the CAG and published in 2007. It is anticipated that they will serve as guidelines for future endoscopic training programs. The present summary article will outline some of the key issues in quality indicators as they pertain particularly to colonoscopy, which has rapidly become the most common endoscopic

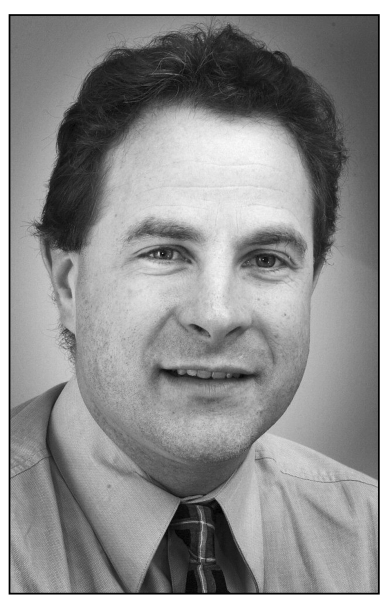

Dr Robert Enns
In a study assessing 12 trainees (seven gastroenterology fellows and five fourth-year surgical residents), Cass et al (8-10) published data in 1993 regarding proficiency with procedure performed. The present article is not an exhaustive review, but instead simply familiarizes the endoscopist with some of the issues that are critical in this area. There are five areas that need to be assessed when considering quality indicators in colonoscopy:

- Training and credentialing;

- Cecal intubation rates;

- Adenoma detection rates;

- Missed cancers and adenomas; and

- Complications.

Although all five of these areas will be discussed, it should be recognized that there is no single 'gold-standard' used to guide the presumed technical 'competence' of an endoscopist. Rather, there are a number of criteria which, when combined, may be used to determine an overall assessment of quality. Other areas that are also important, such as appropriate documentation, will not be discussed here. endoscopic procedures, including how many procedures are required. In this prospective, cross-sectional study, the trainees were graded on their colonoscopy skills with regard to traversing the splenic flexure, intubating the cecum and recognizing abnormalities within the colon. At the time of publication, it was thought by some societies that adequate training might require just 25 procedures. It was found that colonoscopy took a mean duration of 55 min even after 100 procedures. At 100 procedures of training, abnormality detection rates of only $85 \%$, and cecal intubation rates of $84 \%$ were noted. There appeared to be a correlation between the number of procedures and cecal intubation, because the two fellows who had more experience $(210$ procedures and 275 procedures, respectively) were able to intubate the cecum at $94 \%$ and $96 \%$ of the time.

In a second study on colonoscopy training by Marshall et al (11), the duration of the procedure performed by gastroenterology fellows was determined. In our present high-volume endoscopy units, efficiency is critical and, therefore, this study has practical considerations. The study evaluated firstand second-year gastroenterology fellows during their final seven months of each year, and determined the frequency of procedures in which the fellows reached the cecum in less than $30 \mathrm{~min}$. The first-year fellows intubated the cecum in less than $30 \mathrm{~min}$ in $54 \%$ of cases (mean number of colons attempted was 149), whereas the second-year fellows obtained this in $86 \%$ of cases (mean number of colons attempted was 328). Interestingly, the attending staff were able to intubate the cecum in $97 \%$ of cases, leading to the conclusion that there is a linear correlation between the number of training cases and cecal intubation (in less than $30 \mathrm{~min}$ ), and that this improvement continues even after training is complete. The actual number of procedures in 
this study that were required to consistently complete the procedure in less than 30 min was far in excess of what many training programs may offer.

In 1996, Chak et al (12) evaluated the cecal intubation rates of their first-and second-year fellows compared with attending gastroenterologists. Second-year trainees who had performed a mean of 123 colonoscopies in their first year still required assistance to complete the procedure in 36\% of their cases. Second-year fellows attained an $84 \%$ cecal intubation rate. First-year fellows required assistance in $92 \%$ of their procedures, took longer to complete the procedure and additionally required more manoeuvres (ie, position changes of the patient) to complete the procedure. The authors concluded that if cecal intubation was desired to be greater than $90 \%$, with a median duration of less than 15 min to reach the cecum, then over 100 procedures were required.

In defining continuous quality improvement targets for colonoscopy, the US Multi-Society Task Force on Colorectal Cancer (3) indicated the following parameters of optimal practice: cecal intubation rates of more than $90 \%$ in all cases and $95 \%$ in screening cases, and $100 \%$ documentation in endoscopic reports of cecal intubation and visualized landmarks with photography.

However, it is unclear whether cecal intubation should be the key marker one uses to judge competence. Clearly there are many reasons why the cecum cannot be intubated in all patients and just because one physician has a higher intubation rate than another, this does not necessarily ensure adequate or superior endoscopic competence. In clinical practice, even in academic centres, the cecal intubation rates may be much lower than actually expected. In a 'reallife' study by Cotton et al (13), of 69 endoscopists at seven major centres, only $55 \%$ of endoscopists achieved cecal intubation of over $90 \%$ and mean time to completion of procedure took more than $40 \mathrm{~min}$ among $27 \%$ of the endoscopists. With $9 \%$ of endoscopists, cecal intubation was less than $80 \%$.

A more recent study by Aslinia et al (14) was more encouraging for cecal intubation because the six-year audit of cecal intubation was over $90 \%$. Inadequate bowel preparation, inpatient status, abnormal imaging as an indication for colonoscopy, and female sex predicted lower odds of reaching the cecum. This study did not demonstrate that high volume practice was required to maintain high cecal intubation rates. The most common reasons for incomplete procedures were excessive looping and poor colonic preparation. On the other hand, a previous study at the Mayo Clinic (15) showed that cecal intubation rates increase with increasing years of experience (median greater than nine years). Endoscopists with fewer than five years of experience, performing over 200 colonoscopies/year had higher completion rates compared with those doing less than 200 procedures/year (15). This study suggested that high volume physicians appeared to have improved completion rates.

Variable adenoma detection rates is another marker that is used in assessing competency in colonoscopy. These variable rates have been noted in several studies despite the fact that the patients appear to be demographically similar. In a United Kingdom flexible sigmoidoscopy study (16), rates among physicians varied between 10 and 22 adenomas per 100 examinations. A second study from the Mayo clinic (17) demonstrated that higher adenoma rates were associated with longer colonoscopy withdrawal times. In general, for a routine standard screening colonoscopy practice, the incidence of adenomas should be predictable and, if this rate is not routinely obtained by the colonoscopist, concern for missed lesions may be expressed.

Presently, the most prominent issue regarding quality indicators in colonoscopy has to do with withdrawal times. It has been demonstrated in tandem colonoscopy studies $(18-22)$ that miss rates of adenomas $6 \mathrm{~mm}$ to $9 \mathrm{~mm}$ in size may be as high as $13 \%$, with miss rates as high as $27 \%$ for polyps less than $5 \mathrm{~mm}$ in size.

Additionally, miss rates on colonoscopy for colon cancer in a Canadian study were $4 \%(23,24)$. With the recognition that there appeared to be significant miss rates with the 'gold-standard' of visualization (ie, optical colonoscopy), a study was designed to assess whether withdrawal times may be a factor in missing colonic lesions. Previous studies (25) had clearly suggested that endoscopic technique was important and in fact that examination times may be important.

The study by Barclay et al (1) evaluated 12 experienced gastroenterologists who performed almost 8000 colonoscopies. The study concentrated on withdrawal times and compared procedures with withdrawal times of less than 6 min with those that had withdrawal times of greater than 6 min. Neoplastic lesions were seen in $23.5 \%$ of patients, which was deemed to be relatively typical of this patient group, considering the demographics. Detection rates among gastroenterologists, however, varied considerably between 0.10 and 1.05 lesions per patient or between $9.4 \%$ and $32.7 \%$ of patients with adenomas. Colonoscopists with withdrawal times of less than 6 min had lower adenoma detection rates than those with withdrawal times of greater than 6 min (28.3\% versus $11.8 \%$; $\mathrm{P}<0.001)$. Even if subdivided into advanced neoplasia, the group with lower withdrawal times had higher detection rates (6.4\% versus $2.6 \% ; \mathrm{P}=0.005)$. They concluded that in this large community-based gastroenterology practice, greater rates of detection of adenomas were observed among endoscopists who had longer mean times for withdrawal of the colonoscope'.

The reasons for selection of $6 \mathrm{~min}$ for the withdrawal time is unclear. Nonetheless, the principle is clear, which is that the rapidity of the procedure may affect polyp detection. In our present system, where maximum efficiency is demanded to enhance remuneration, it must be recognized that the key to a 'good' colonoscopy is firstly, to detect lesions that may adversely affect downstream morbidity and mortality. It behooves us, therefore to recognize the limitations of our procedures and take steps to maximize our yield of adenoma detection.

Complications are relatively uncommon in colonoscopy, but they are potentially serious. Additionally, because the volume of patients undergoing the procedure is so high, even rare complications become important. The most important complications include bleeding and perforation (26-34). A recent publication (34) demonstrated in a retrospective fashion that complications occurred less frequently in a patient group who did not undergo biopsy or polypectomy (0.8 of 1000 procedures versus 5.0 of 1000 procedures). Perforations occurred in 0.9 of 1000 colonoscopies and bleeding in 4.8 of 1000 colonoscopies, with endoscopic biopsy or polypectomy demonstrating increased risk in all 
categories. There are a number of factors that have been demonstrated to increase the risk of bleeding in colonoscopy including advancing age, comorbid disease, use of anticoagulants and increasing size of the polyp (35).

Although our quality indicators for colonoscopy are not standardized, there is evidence behind their use. There is support for each one described above and, with our ever increasing volume of these procedures, it is critical that understanding and subsequently applying these procedures to training as well as our daily practice is paramount in enhancing our patients' care. Many centres have already instituted withdrawal times within their daily endoscopy

\section{REFERENCE}

1. Barclay RL, Vicari JJ, Doughty AS, Johanson JF, Greenlaw RL. Colonoscopic withdrawal times and adenoma detection during screening colonoscopy. N Engl J Med 2006;355:2533-41.

2. Lieberman D. A call to action - measuring the quality of colonoscopy. N Engl J Med 2006;355:2588-9.

3. Rex DK, Bond JH, Winawer S, et al; US Multi-Society Task Force on Colorectal Cancer. Quality in the technical performance of colonoscopy and the continuous quality improvement process for colonoscopy: Recommendations of the US Multi-Society Task Force on Colorectal Cancer. Am J Gastroenterol 2002;97:1296-308.

4. Rex DK, Petrini JL, Baron TH, et al; ASGE/ACG Taskforce on Quality in Endoscopy. Quality indicators for colonoscopy. Am J Gastroenterol 2006;101:873-85.

5. Wexner SD, Eisen GM, Simmang C. Principles of privileging and credentialing for endoscopy and colonoscopy. Surg Endosc 2002;16:367-9.

6. Wexner SD, Eisen GM, Simmang C; Society of American Gastrointestinal Endoscopic Surgeons Credentials Committee; American Society for Gastrointestinal Endoscopy Standards of Practice Committee; American Society of Colon and Rectal Surgeons Standards Committee. Principles of privileging and credentialing for endoscopy and colonoscopy. Dis Colon Rectum 2002;45:161-4.

7. Wexner SD, Litwin D, Cohen J, et al; American Society for Gastrointestinal Endoscopy, Society of American Gastrointestinal Endoscopic Surgeons, American Society of Colorectal Surgeons. Principles of privileging and credentialing for endoscopy and colonoscopy. Gastrointest Endosc 2002;55:145-8.

8. Cass OW. Training to competence in gastrointestinal endoscopy: A plea for continuous measuring of objective end points. Endoscopy 1999;31:751-4.

9. Cass OW. Objective evaluation of competence: Technical skills in gastrointestinal endoscopy. Endoscopy 1995;27:86-9.

10. Cass OW, Freeman ML, Peine CJ, Zera RT, Onstad GR. Objective evaluation of endoscopy skills during training. Ann Intern Med 1993;118:40-4.

11. Marshall JB. Technical proficiency of trainees performing colonoscopy: A learning curve. Gastrointest Endosc 1995;42:287-91.

12. Chak A, Cooper GS, Blades EW, Canto M, Sivak MV Jr. Prospective assessment of colonoscopic intubation skills in trainees. Gastrointest Endosc 1996;44:54-7.

13. Cotton PB, Connor P, McGee D, et al. Colonoscopy: Practice variation among 69 hospital-based endoscopists. Gastrointest Endosc 2003;57:352-7.

14. Aslinia F, Uradomo L, Steele A, Greenwald BD, Raufman JP. Quality assessment of colonoscopic cecal intubation: An analysis of 6 years of continuous practice at a university hospital. Am J Gastroenterol 2006;101:721-31.

15. Harewood GC. Relationship of colonoscopy completion rates and endoscopist features. Dig Dis Sci 2005;50:47-51.

16. Atkin W, Rogers P, Cardwell C, et al. Wide variation in adenoma detection rates at screening flexible sigmoidoscopy. Gastroenterology 2004;126:1247-56. schedules. More study is needed in all of these areas to solidify our understanding of which factors are the most important. The use of $6 \mathrm{~min}$ for withdrawal, although important, does not take into account many other factors (such as the difficulty of the colon, preparation and presence of diverticuli) which may play a significant role in how long the withdrawal time should be.

Despite these limitations, the institution of quality assurance for all endoscopy units should be mandated to maximize procedure efficacy and, thereby, give full confidence in the procedure to both the physician and the patient.

17. Sanchez W, Harewood GC, Petersen BT. Evaluation of polyp detection in relation to procedure time of screening or surveillance colonoscopy. Am J Gastroenterol 2004;99:1941-5.

18. Haseman JH, Lemmel GT, Rahmani EY, Rex DK. Failure of colonoscopy to detect colorectal cancer: Evaluation of 47 cases in 20 hospitals. Gastrointest Endosc 1997;45:451-5.

19. Rex DK, Cutler CS, Lemmel GT, et al. Colonoscopic miss rates of adenomas determined by back-to-back colonoscopies. Gastroenterology 1997;112:24-8.

20. Hixson LJ, Fennerty MB, Sampliner RE, McGee DL, Garewal H. Two-year incidence of colon adenomas developing after tandem colonoscopy. Am J Gastroenterol 1994;89:687-91.

21. Hixson LJ, Fennerty MB, Sampliner RE, Garewal HS. Prospective blinded trial of the colonoscopic miss-rate of large colorectal polyps. Gastrointest Endosc 1991;37:125-7.

22. Hixson LJ, Fennerty MB, Sampliner RE, McGee D, Garewal H. Prospective study of the frequency and size distribution of polyps missed by colonoscopy. J Nat Cancer Inst 1990;82:1769-72.

23. Bressler B, Paszat LF, Chen Z, Rothwell DM, Vinden C, Rabeneck L. Rates of new or missed colorectal cancers after colonoscopy and their risk factors: A population-based analysis. Gastroenterology 2007;132:96-102.

24. Bressler B, Paszat LF, Vinden C, Li C, He J, Rabeneck L. Colonoscopic miss rates for right-sided colon cancer: A populationbased analysis. Gastroenterology 2004;127:452-6.

25. Rex DK. Colonoscopic withdrawal technique is associated with adenoma miss rates. Gastrointest Endosc 2000;51:33-6.

26. Araghizadeh FY, Timmcke AE, Opelka FG, Hicks TC, Beck DE. Colonoscopic perforations. Dis Colon Rectum 2001;44:713-6.

27. Cobb WS, Heniford BT, Sigmon LB, et al. Colonoscopic perforations: Incidence, management, and outcomes. Am Surg 2004;70:750-7.

28. Dafnis G, Ekbom A, Pahlman L, Blomqvist P. Complications of diagnostic and therapeutic colonoscopy within a defined population in Sweden. Gastrointest Endosc 2001;54:302-9.

29. Dominitz JA, Eisen GM, Baron TH, et al; Standards of Practice Committee. American Society for Gastrointestinal Endoscopy. Complications of colonoscopy. Gastrointest Endosc 2003;57:441-5.

30. Fraser C, Saunders B. Preventing postpolypectomy bleeding: Obligatory and optional steps. Endoscopy 2004;36:898-900.

31. Gatto NM, Frucht H, Sundararajan V, Jacobson JS, Grann VR, Neugut AI. Risk of perforation after colonoscopy and sigmoidoscopy: A population-based study. J Natl Cancer Inst 2003;95:230-6.

32. Korman LY, Overholt BF, Box T, Winker CK. Perforation during colonoscopy in endoscopic ambulatory surgical centers. Gastrointest Endosc 2003;58:554-7.

33. Kuznets N. Diagnostic colonoscopy: Performance measurement study. J Ambul Care Manage 2002;25:41-55.

34. Levin TR, Zhao W, Conell C, et al. Complications of colonoscopy in an integrated health care delivery system. Ann Intern Med 2006;145:880-6.

35. Kim HS, Kim TI, Kim WH, et al. Risk factors for immediate postpolypectomy bleeding of the colon: A multicenter study. Am J Gastroenterol 2006;101:1333-41. 


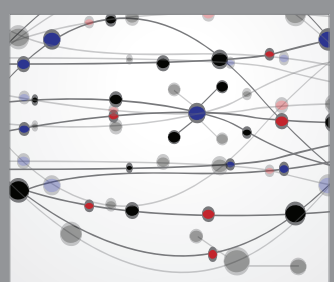

The Scientific World Journal
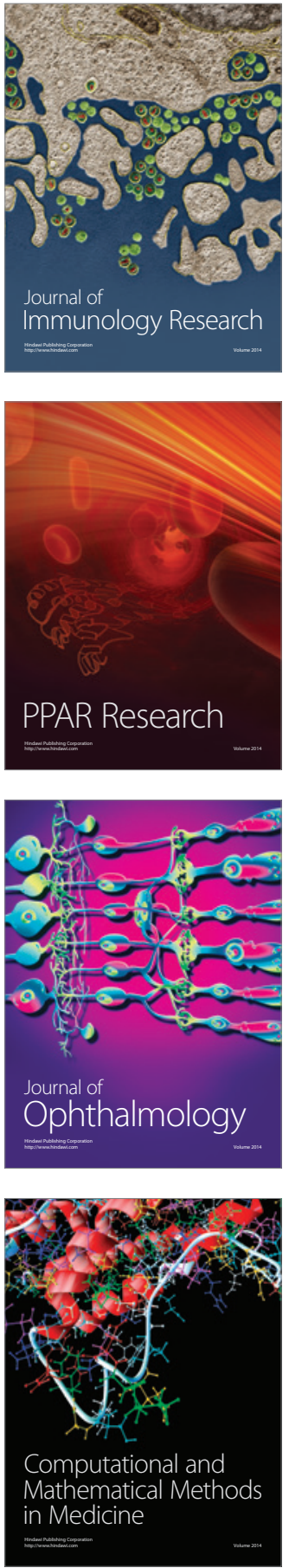

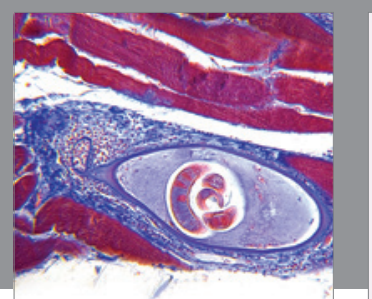

Gastroenterology Research and Practice

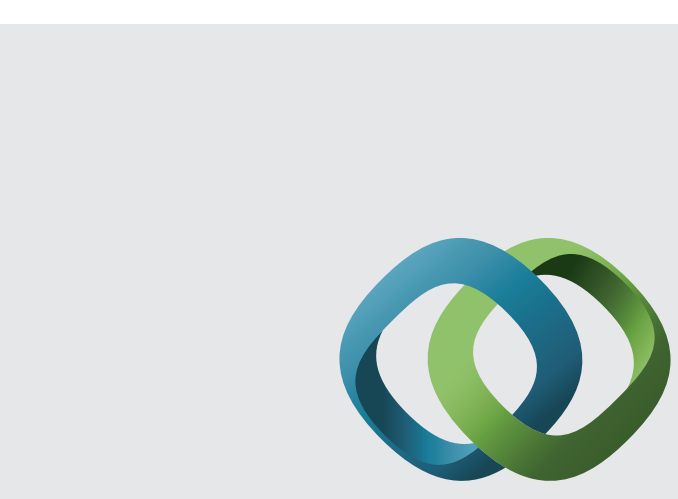

\section{Hindawi}

Submit your manuscripts at

http://www.hindawi.com
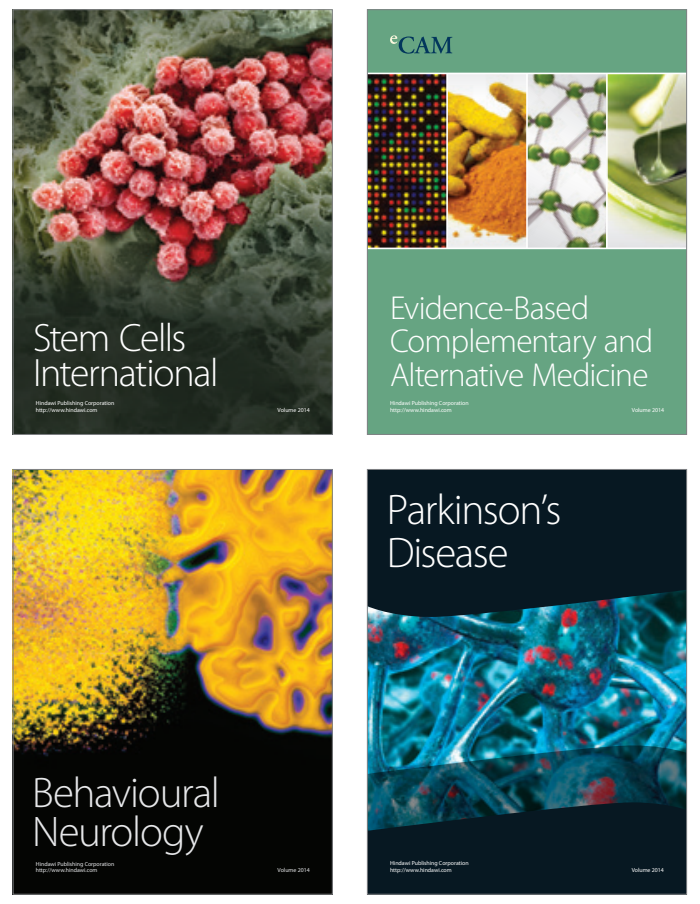
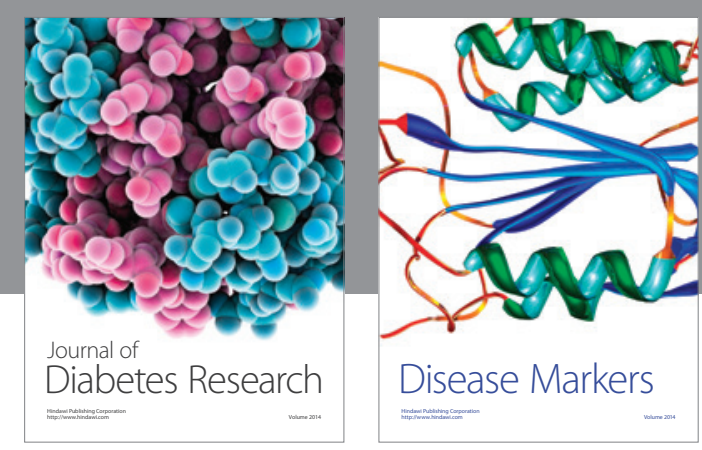

Disease Markers
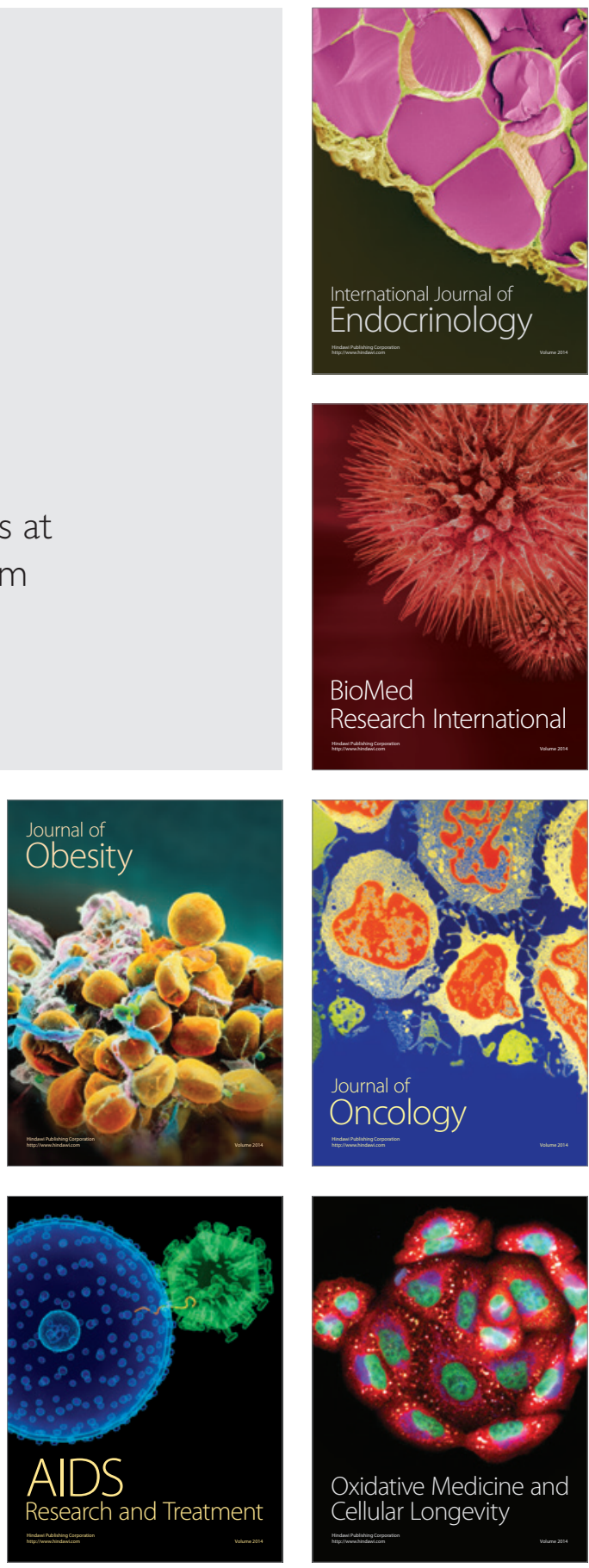